\title{
ESTIOLAMENTO NA MICROPROPAGAÇÃO DO ABACAXIZEIRO CV. PÉROLA
}

\author{
MARIA APARECIDA MOREIRA ${ }^{1}$ \\ MOACIR PASQUAL ${ }^{2}$ \\ JANICE GUEDES DE CARVALHO \\ CHRYSTIANE BORGES FRÁGUAS ${ }^{4}$
}

\begin{abstract}
RESUMO - Objetivou-se estudar o efeito do estiolamento na micropropagação de abacaxizeiro cv. Pérola e posterior recuperação dos brotos estiolados, realizandose dois experimentos. No primeiro, os caules utilizados como explantes foram obtidos de brotos préestabelecidos in vitro, dos quais foram retiradas as folhas. O estiolamento foi induzido colocando-se os explantes em tubos de ensaio no escuro por 20, 40 e 80 dias, contendo os seguintes meios de cultura: 1) MS suplementado com $0,1 \mathrm{mg} . \mathrm{L}^{-1}$ de ANA e $0,5 \mathrm{mg} . \mathrm{L}^{-1}$ de BAP, 2) MS suplementado com 1,8 mg. $\mathrm{L}^{-1}$ de ANA e 2 mg. $\mathrm{L}^{-1}$ de BAP e 3) MS sem reguladores de crescimento. Para número de brotos, o melhor meio foi o $\mathrm{MS}+$ 1,8 mg. $\mathrm{L}^{-1}$ de ANA e 2 mg. $\mathrm{L}^{-1}$ de BAP, obtendo-se mé-
\end{abstract}

dia de 10,26 brotações aos 40 dias no escuro. Para comprimento de brotos estiolados, o meio MS sem reguladores de crescimento foi significativamente melhor quando os explantes foram mantidos por 80 dias no escuro, apresentando comprimento médio de $10,86 \mathrm{~cm}$. No segundo experimento, os brotos estiolados, com e sem o ápice, foram colocados horizontalmente em placas contendo meios de cultura com idêntica formulação aos descritos anteriormente. Para número total de brotos, brotações estioladas sem ápice em meio MS suplementado com 1,8mg. $\mathrm{L}^{-1}$ de ANA e $2 \mathrm{mg} . \mathrm{L}^{-1}$ de BAP promoveram o melhor resultado, correspondendo a 10,61 brotações por explante.

TERMOS PARA INDEXAÇÃO: Ananas comosus, cultura de tecidos, propagação, Bromeliaceae, ausência de luz.

\section{ETIOLATED IN MICROPROPAGATION OF CV. PÉROLA PINEAPPLE PLANT}

\begin{abstract}
It was aimed to produce micropropagated plantlets of pineapple cv. Pérola by using the etiolated technique and subsequent recovery of etiolated shoots. Two experiments were carried out. In the first, the stalks used as explant were obtained from in vitro shoots established without leaves. The etiolation was induced by putting the explants in test tubes in the darkness for 20, 40 and 80 days with the media: 1) MS supplemented with ANA 0.1mg. $\mathrm{L}^{-1}$ and BAP 0.5mg. $\mathrm{L}^{-1}, 2$ ) MS supplemented with ANA $1.8 \mathrm{mg} . \mathrm{L}^{-1}$ and BAP $2 \mathrm{mg} . \mathrm{L}^{-1}$ and 3) MS without growth regulators. The best results for shoot number were
\end{abstract}

obtained with $\mathrm{MS}+$ ANA $1.8 \mathrm{mg} . \mathrm{L}^{-1}$ and BAP $2 \mathrm{mg} . \mathrm{L}^{-1}$ media (10.26 shoots at 40 days in the darkness). The MS medium without growth regulators, was significantly better for etiolated shoots when the explants were maintained for 80 days in the darkness, presenting $10.86 \mathrm{~cm}$ mean length. In the second experiment, the etiolated shoots, with or without apex, were put horizontally in plates containing the three culture media described before. The MS medium supplemented with ANA $1.8 \mathrm{mg} . \mathrm{L}^{-1}$ and BAP $2 \mathrm{mg} . \mathrm{L}^{-1}$ induced the best result for total shoots number (10.61 shoots when the apex were eliminated).

INDEX TERMS: Ananas comosus, tissue culture, propagation, Bromeliaceae, light absence.

\footnotetext{
1. Engenheiro Agrônomo, Pós-Graduanda. UNIVERSIDADE FEDERAL DE LAVRAS/UFLA - Caixa Postal 37 37200-000 - Lavras, MG, bianch@bol.com.br

2. Professor Titular - Departamento de Agricultura/UFLA, mpasqual@ufla.br

3. Professor Titular - Departamento de Ciências do Solo/UFLA.

4. Engenheiro Agrônomo, Mestranda - DAG/UFLA.
} 


\section{INTRODUÇÃO}

A micropropagação do abacaxizeiro consiste, basicamente, em desfolhar as mudas, desinfestar com hipoclorito de sódio os caules obtidos, retirar as gemas em ambiente asséptico, as quais são novamente desinfestadas e colocadas em tubos de ensaio contendo meio nutritivo para que ocorra a brotação. Gemas axilares dormentes da coroa são excelentes explantes primários, além de folhas apicais e mudas obtidas in vitro, que são bons materiais para produção de calos, a partir dos quais mudas podem ser regeneradas (MATHEWS e RANGAN, 1981). Gemas apicais e axilares da coroa (MATHEWS e RANGAN, 1979), de filhotes (SITA et al., 1974), gemas laterais (ZEPEDA e SAGAWA, 1981), sincárpio (WAKASA, 1979 citado por KISS et al., 1995) e calos (RAO et al., 1981; WEE, 1979, citados por KISS et al., 1995) também são utilizados.

$\mathrm{Na}$ maioria dos trabalhos, o meio MS (MURASHIGE, 1974) tem sido utilizado. Vários reguladores de crescimento têm sido testados para iniciação e manutenção das plântulas no meio de cultura, especialmente combinação de auxina/citocinina (MOORE et al., 1992; PESCADOR e KOLLER, 1992; CABRAL et al., 1984). Moore et al. (1992) indicam o meio MS suplementado com 3\% de sacarose, 0,8\% de ágar, 0,57 $\mathrm{mM}$ inositol, 1,2 $\mu \mathrm{M}$ de tiaminaHCl, 10,8 $\mu \mathrm{M}$ de ANA e $8,8 \mu \mathrm{M}$ de BAP.

A micropropagação do abacaxizeiro é normalmente mais demorada que outras espécies, pois a produção de plantas não é conseguida antes de 9 a 12 meses depois do início das culturas. Mas esse obstáculo pode ser superado com novos estudos para reduzir esse tempo. Nesse sentido, Kiss et al. (1995) propuseram novo método de propagação rápida do abacaxi, baseado no alongamento de brotos induzidos in vitro, por meio do estiolamento.

O estiolamento é o desenvolvimento de brotos, ramos ou partes desses em ausência de luz, o que causa o crescimento, geralmente alongado e com coloração amarela ou branca, em razão da ausência de clorofila (HARTMANN e KESTER, 1990).

Os efeitos morfológicos incluem a coloração branca, alongamento dos internódios e aumento da suculência, proporcionando decréscimo na barreira mecânica dos tecidos do caule em consequiência da menor lignificação, suberificação e espessura das paredes celulares (MAYNARD e BASSUK, 1996). O estiolamento atrasa a lignificação dos tecidos, e essa redução das propriedades mecânicas dos tecidos é responsável pela facilidade de enraizamento provocada nas brotações es- tioladas (BASSUK e MAYNARD, 1987, citados por BIASI, 1996).

Os efeitos fisiológicos incluem o metabolismo e transporte de auxina, alterações na sensibilidade dos tecidos à auxina e alterações no conteúdo de compostos fenólicos. Acredita-se que a luz diminui a eficiência do AIA (ácido indolacético), sem mudar o seu conteúdo (MAYNARD e BASSUK, 1988).

Em cultivos in vitro, Economou e Read (1987) encontraram maior porcentagem de enraizamento em brotações de azaléa cultivadas sob menor irradiação, e uma alta correlação foi encontrada entre a atividade da peroxidase e a habilidade de enraizamento das brotações.

O método de micropropagação do abacaxizeiro proposto por Kiss et al. (1995) é baseado no alongamento de brotos induzidos in vitro mediante estiolamento, em que brotos da cv. Smooth Cayenne produzidos 'in vitro' foram colocados em meio MS adicionado de ANA $(10 \mu \mathrm{M})$ e mantidos a $28^{\circ} \mathrm{C}$ no escuro por 30 a 40 dias, após retiradas todas as folhas. Esse processo promoveu o estiolamento dos brotos e indução de novas gemas. Depois de estiolados, os brotos foram colocados em placas de Petri, no sentido horizontal, contendo meio de cultura N6 suplementado com cinetina $(25 \mu \mathrm{M})$ ou BAP $(20 \mu \mathrm{M})$, obtendo após 4 a 6 semanas, uma taxa de regeneração de 13 a 15 plantas por nó, aumentando a taxa de multiplicação 'in vitro'. Com esse mesmo objetivo, Moreira et al. (1997), usando brotos cortados, sem folhas, de plantas já estabelecidas 'in vitro' da cv. Primavera, conseguiram maior estiolamento $(10,26 \mathrm{~cm})$ dos brotos aos 45 dias de incubação no escuro.

Realizou-se este trabalho com o objetivo de obter brotações in vitro de abacaxizeiro cv. Pérola mediante estiolamento de brotos.

\section{MATERIAL E MÉTODOS}

Brotações de abacaxizeiro cv. Pérola estabelecidas 'in vitro' foram selecionadas e colocadas em meio de cultura MS. Dessas, após retiradas as folhas e raízes, obtiveram-se caules de aproximadamente $1 \mathrm{~cm}$ de comprimento que, em condições assépticas, foram colocados em tubos de ensaio de $150 \times 25 \mathrm{~mm}$ contendo os meios de cultura.

No primeiro experimento, os tratamentos consistiram dos seguintes meios de cultura: 1) MS suplementado com 1,8 mg. $\mathrm{L}^{-1}$ de ANA e 2 mg. $\mathrm{L}^{-1}$ de BAP; 2 ) MS com 0,1 mg.. $\mathrm{L}^{-1}$ de ANA e 0,5 mg. $\mathrm{L}^{-1}$ de BAP e 3) MS sem reguladores de crescimento. $\mathrm{O}$ estiolamento foi induzido colocando-se os caules nos tubos de ensaio contendo 
os meios de cultura, envoltos em papel alumínio, para proporcionar a condição de escuro por 20, 40 e 80 dias.

$\mathrm{O}$ delineamento experimental utilizado foi o inteiramente casualizado com 9 tratamentos, 5 repetições e 3 brotos/repetição, totalizando 135 explantes. Ao término de cada período de escuro, foram avaliados número e comprimento dos brotos estiolados.

Para o segundo experimento, brotações foram colocadas em meio MS e mantidas em condição de escuro, por 80 dias, para promover o estiolamento, conforme resultado obtido no experimento anterior. Após estiolados, os brotos de aproximadamente $12 \mathrm{~cm}$, foram colocados horizontalmente em placas de Petri, visando à brotação das gemas, contendo os seguintes meios de cultura: 1) MS suplementado com 1,8 mg. $\mathrm{L}^{-1}$ de ANA e 2 mg. $\mathrm{L}^{-1}$ de BAP 2) MS suplementado com 0,1 mg. $\mathrm{L}^{-1}$ de ANA e 0,5 mg. $\mathrm{L}^{-1}$ de BAP e 3 ) MS sem reguladores de crescimento. Outro fator testado foi a retirada ou não do ápice dos brotos estiolados, visto que, em testes preliminares, essa técnica proporcionou maior brotação.

$\mathrm{O}$ delineamento experimental utilizado foi o inteiramente casualizado em esquema fatorial $3 \times 2$, com 3 repetições e 3 brotos/repetição. Após 45 dias em sala de crescimento, avaliaram-se o número total de brotações (NTB), número de brotações na base (NBB), número de brotações no ápice (NBA) e número de brotações entre o ápice e a base (NBAB).

\section{RESULTADOS E DISCUSSÃO}

\section{Experimento 1}

Para número de brotos (Tabela 1), os três meios utilizado promoveram comportamento semelhante aos explantes, aos 20 dias no escuro. Aos 40 e 80 dias no escuro, os explantes mostraram-se diferentes, e aos 40 dias, no meio 1 , foram superiores, apresentando número médio de 10,26 brotações, e aos 80 dias, no meio 2 , apresentaram maior número médio de brotações $(8,19)$. No meio 3 (sem reguladores de crescimento), os explantes tiveram comportamento inferior, independente do período no escuro, apresentando um máximo de 2,49 brotações.

Apesar de o meio MS suplementado com 1,8 mg. $\mathrm{L}^{-1}$ de ANA e 2,0 mg. $\mathrm{L}^{-1}$ de BAP ter induzido maior brotação aos 20 e 40 dias, verificou-se expressiva presença de calos nos explantes cultivados nesse meio. Provavelmente a concentração da auxina utilizada foi elevada, visto que o ácido indolacético (ANA) é uma auxina que, se adicionada em concentrações acima de alguns décimos de miligrama, tende à formação de calos nos explantes. O meio suplementado com $0,1 \mathrm{mg} . \mathrm{L}^{-1}$ de ANA + 0,5 mg.L $\mathrm{L}^{-1}$ de BAP, apesar de induzir um núme- ro menor de brotações aos 20 e 40 dias, não promoveu formação de calos.

TABELA 1 - Número médio de brotações estioladas de abacaxizeiro cv. Pérola submetidos a diferentes tempos de escuro e meios de cultura. UFLA, LavrasMG, 2002.

\begin{tabular}{cccc}
\hline \multirow{2}{*}{$\begin{array}{c}\text { Tempo de escuro } \\
\text { (dias) }\end{array}$} & \multicolumn{3}{c}{ Meio de Cultura } \\
\cline { 2 - 4 } & $\mathbf{1}$ & $\mathbf{2}$ & $\mathbf{3}$ \\
\hline 20 & $4,39 \mathrm{a}$ & $2,36 \mathrm{a}$ & $2,49 \mathrm{a}$ \\
40 & $10,26 \mathrm{a}$ & $6,33 \mathrm{~b}$ & $2,29 \mathrm{c}$ \\
80 & $3,96 \mathrm{~b}$ & $8,19 \mathrm{a}$ & $1,26 \mathrm{c}$ \\
\hline
\end{tabular}

Médias seguidas por letras distintas, na mesma linha, diferem entre si ao nível de $5 \%$ de probabilidade.

Quando se utilizou o meio MS suplementado com 1,8 mg. $\mathrm{L}^{-1}$ de ANA e $2 \mathrm{mg} . \mathrm{L}^{-1}$ de BAP, o número médio máximo de brotações $(10,78)$ foi conseguido aos 49,3 dias e, para o meio MS suplementado com $0,1 \mathrm{mg} . \mathrm{L}^{-1}$ de ANA e $0,5 \mathrm{mg} . \mathrm{L}^{-1}$ de BAP, o número médio máximo de brotos $(8,19)$ foi obtido aos 80 dias no escuro. Os resultados obtidos foram superiores aos obtidos por Kiss et al. (1995), em razão, provavelmente, da adição de BAP nos meios, pois esse regulador está diretamente envolvido na indução de brotações. $\mathrm{O}$ meio 3 (sem reguladores de crescimento) induziu um decréscimo no número de brotações com o aumento do tempo de escuro.

O meio MS sem fitoreguladores foi significativamente melhor para comprimento de brotos estiolados aos 40 e 80 dias de escuro (Tabela 2). Quando mantidos durante 20 dias no escuro, os três meios tiveram estatisticamente o mesmo comportamento. Praxedes et al. (2000) verificaram que o estiolamento 'in vitro' do abacaxizeiro cv. Pérola pode ser obtido sem a aplicação exógena de ANA e AIA. Porém, Sá et al. (2000) observaram que o maior comprimento dos segmentos estiolados $(4,3 \mathrm{~cm})$ foi obtido com $10 \mu \mathrm{M}$ de BAP $+10 \mu \mathrm{M}$ de ANA.

Nos meios de cultura 1 e 2 , não se observou incremento no comprimento dos brotos em função do tempo de escuro, ao passo que, no meio sem regulador de crescimento (3), houve acréscimo no comprimento até os 30 dias.

O comprimento dos brotos estiolados é uma variável importante, pois está diretamente relacionada com o número de nós que serão recuperados em novas brota- 
ções, quando colocados em condições de luz. Brotos estiolados de aproximadamente $12 \mathrm{~cm}$ apresentaram entre 10 a 12 nós. Para a cv. Smooth Cayenne, os brotos estiolados atingiram comprimento de 6 a $10 \mathrm{~cm}$, com 6 a 9 nós por broto, depois de mantidos por 30 a 35 dias no escuro (KISS et al., 1995).

O tempo de estiolamento obtido com a cv. Perola foi maior em relação às cvs. Primavera (MOREIRA et al. 1997) e Smooth Cayenne (KISS et al., 1995).

TABELA 2 - Comprimento médio de brotações estioladas de abacaxizeiro cv. Pérola submetidas a diferentes tempos de escuro e meios de cultura. UFLA, LavrasMG, 2002.

\begin{tabular}{cccc}
\hline \multirow{2}{*}{$\begin{array}{c}\text { Tempo de escuro } \\
\text { (dias) }\end{array}$} & \multicolumn{3}{c}{ Meios de cultura } \\
\cline { 2 - 4 } & $\mathbf{1}$ & $\mathbf{2}$ & $\mathbf{3}$ \\
\hline 20 & $0,30 \mathrm{a}$ & $0,65 \mathrm{a}$ & $1,01 \mathrm{a}$ \\
40 & $0,52 \mathrm{a}$ & $0,72 \mathrm{a}$ & $2,60 \mathrm{~b}$ \\
80 & $0,84 \mathrm{a}$ & $1,36 \mathrm{a}$ & $10,86 \mathrm{~b}$ \\
\hline
\end{tabular}

Médias seguidas por letras distintas, na mesma linha, diferem entre si ao nível de $5 \%$ de probabilidade.

\section{Experimento 2}

Para número total de brotos (NTB), os meios proporcionaram o mesmo comportamento aos explantes quando se manteve o ápice (Tabela 3). Entretanto, quando o ápice foi retirado, os meios foram significativamente diferentes, e os explantes tiveram maior média de brotação no meio MS suplementado com 1,8 mg. $\mathrm{L}^{-1}$ de ANA e 2 mg.L -1 $^{-1}$ de BAP (2), apresentando média de brotações de 10,61 , porém com calos em todos os nós, seguido pelo meio MS suplementado com $0,1 \mathrm{mg} . \mathrm{L}^{-1} \mathrm{de}$ ANA e $0,5 \mathrm{mg} . \mathrm{L}^{-1}$ de BAP, com média de 8,10 brotações. Sá et al. (2000) constataram maiores taxas de regeneração com dosagens de 5 (27,3 brotos) e $10 \mu \mathrm{M}$ (27 brotos) de BAP nos segmentos que foram seccionados.

Para número de brotos no ápice (NBA) e na base (NBB), os explantes tiveram o mesmo comportamento nos três meios quando foi deixado o ápice e foram diferentes quando o retiraram (Tabela 3), sendo superiores nos meios 2 e 3 .

Para a variável número de brotos entre o ápice e a base (NBAB), não houve diferença significativa, obtendo-se 3,33 brotações com a retirada do ápice e quando se utiliza o meio MS suplementado com $0,1 \mathrm{mg} . \mathrm{L}^{-1}$ de ANA e 0,5mg. $\mathrm{L}^{-1}$ de BAP (Tabela 3).

De maneira geral, o meio MS suplementado com $1,8 \mathrm{mg} . \mathrm{L}^{-1}$ de ANA e $2 \mathrm{mg} . \mathrm{L}^{-1}$ de BAP mostrou-se mais eficiente para indução de brotações nos brotos estiolados, em número, porém com formação de uma grande massa de calos, observada em quase todos os nós. No meio MS suplementado com $0,1 \mathrm{mg} . \mathrm{L}^{-1}$ de ANA e 0,5 mg. $\mathrm{L}^{-1}$ de BAP, as brotações foram menores (peso de aproximadamente $100 \mathrm{mg}$ ), sem formação de calos e mais individualizadas, o que facilitou a repicagem.

Observou-se dificuldade em quebrar a dominância apical dos brotos estiolados para induzir a iniciação de brotações entre os nós. Por causa disso, pode-se propor a individualização de cada nó e a colocação em meio MS suplementado com $0,1 \mathrm{mg} . \mathrm{L}^{-1}$ de ANA e 0,5 mg. $L^{-1}$ de BAP. Outra aplicação do estiolamento pode ser em gemas na fase de isolamento, o que poderia compensar a demora das brotações (em torno de 9 meses) e a taxa de contaminação, que é muito alta.

TABELA 3 - Número total de brotações (NTB), número brotações na ápice (NBA), número de brotações na base $(\mathrm{NBB})$ e número de brotações entre o ápice e a base (NBAB) de brotos estiolados in vitro de abacaxizeiro cv. Pérola, em função da retirada do ápice e do meio de cultura. UFLA, Lavras-MG, 2002.

\begin{tabular}{|c|c|c|c|c|c|c|c|c|}
\hline \multirow{2}{*}{ Meios } & \multicolumn{2}{|c|}{ NTB } & \multicolumn{2}{|c|}{ NBA } & \multicolumn{2}{|c|}{ NBB } & \multicolumn{2}{|c|}{ NBAB } \\
\hline & Com & Sem & Com & Sem & Com & Sem & Com & Sem \\
\hline 1 & $2.33 \mathrm{a} \mathrm{A}$ & 2.88 a A & $1.66 \mathrm{a} \mathrm{A}$ & $0.00 \mathrm{a} \mathrm{B}$ & 0.99 a A & $0.55 \mathrm{a} \mathrm{A}$ & $0.00 \mathrm{a} \mathrm{B}$ & $2.33 \mathrm{a} \mathrm{A}$ \\
\hline 2 & 2.77 a B & $10.61 \mathrm{c} \mathrm{A}$ & $1.22 \mathrm{a} \mathrm{B}$ & $2.44 \mathrm{~b} \mathrm{~A}$ & $1.33 \mathrm{a} \mathrm{B}$ & $4.82 \mathrm{c} \mathrm{A}$ & 0.22 a B & 3.33 a A \\
\hline 3 & 3.33 a B & $8.10 \mathrm{~b} \mathrm{~A}$ & $1.00 \mathrm{a} \mathrm{B}$ & $2.55 \mathrm{~b} \mathrm{~A}$ & $1.66 \mathrm{a} B$ & $3.55 \mathrm{~b} \mathrm{~A}$ & 0.66 a B & $2.66 \mathrm{a} \mathrm{A}$ \\
\hline
\end{tabular}

Médias seguidas por letras diferentes, minúsculas na coluna e maiúsculas na mesma linha, diferem entre si ao nível de $5 \%$ de probabilidade. 


\section{CONCLUSÕES}

a) Para o estiolamento das brotações, o meio de cultura MS suplementado com $1,8 \mathrm{mg} / \mathrm{l}$ de ANA e 2 $\mathrm{mg} / \mathrm{l}$ de BAP proporciona maior taxa de multiplicação. Para o comprimento de brotos estiolados, o melhor meio é o MS, sem reguladores de crescimento, quando os explantes ficam por 80 dias no escuro.

b) $\mathrm{O}$ meio MS suplementado com $1,8 \mathrm{mg} \cdot \mathrm{L}^{-1} \mathrm{de}$ ANA e $2 \mathrm{mg} . \mathrm{L}^{-1}$ de BAP promove maior número de brotações quando se retira o ápice dos brotos estiolados.

\section{REFERÊNCIAS BIBLIOGRÁFICAS}

BIASI, L. A. Emprego do estiolamento na propagação de plantas. Ciência Rural, Santa Maria, v. 26, n. 2, p. 309-314, maio/ago. 1996.

CABRAL, J. R. S.; CUNHA, G. A. P.; RODRIGUES, E. M. Micropropagação do abacaxizeiro. In: CONGRESSO BRASILEIRO DE FRUTICULTURA 5., 1983, Florianópolis. Anais... Florianóplois: Sociedade Brasileira de Fruticultura, v. 5, p. 124-127, 1984.

ECONOMOU, A. S.; READ, P. E. Light treatments to improve efficiency of in vitro propagation systems. HortScience, Alexandria, v. 22, n. 5, p. 751-754, Oct. 1987.

HARTMAnN, H. T.; KESTER, D. E. Propagation de plantas: principios y practicas. México, D. C.: Continental, 1990. 760 p.

KISS, E.; KISS, J.; GYULAI, G.; HESZKY, L. E. A novel method for rapid micropropagation of pineapple. HortScience, Alexandria, v. 30, n. 1, p. 127-129, 1995

MAYNARD, B. K.; BASSUK, N. L. Etiolation and banding effects on adventitious root formation. In: DAVIS, T. R. Adventitious root formation in cuttings. Portland: [s.n.], 1988. v. 2, cap. 2, p. 29-46.

MAYNARD, B. K.; BASSUK, N. L. Effects of stock plant etiolation, shading, banding, and shoot development on histology and cutting propagation of Carpinus betulus L. fastigiata. Journal of the American Society for Horticultural Science, Alexandria, v. 121, n. 5, p. 853860, 1996.

MATHEWS, V. H.; RANGAN, T. S. Multiple plantlets in lateral bud and leaf explant 'in vitro' culture of pineapple. Scientia Horticulturae, Amsterdan, v. 11, n. 4, p. 519-528, 1979.
MATHEWS, V. H.; RANGAN, T. S. Growth and regeneration of plantlets in callus cultures of pineapple. Scientia Horticulturae, Amsterdan, v. 14, p. 227-234, 1981.

MOORE, G. A.; DeWALD, M. G.; EVANS, M. H. Micropropagation of pineapple (Ananas comosus L.). In: BAJAJ, Y. P. S. (Ed.). Biotecnology in agriculture and forestry 18: high-tech and micropropagation II. New York: Springer-Verlag, 1992. p. 461-470.

MOREIRA, M. A.; ANJOS SOBRINHO, A. dos; SILVA, A. B. da; PASQUAL, M. Indução ao estiolamento 'in vitro' de abacaxi cv. Primavera. In: CONGRESSO BRASILEIRO DE FISIOLOGIA VEGETAL, 6., 1997, Belém. Resumos... Belém: Sociedade Brasileira de Fisiologia vegetal, 1997. p. 415.

MURASHIGE, T. Plant propagation through tissue culture. Annual Review of Plant Physiology, Palo Alto, v. 25, p. 135-166, 1974.

PESCADOR, R.; KOLLER, O. C. Propagação 'in vitro' do abacaxizeiro (Ananas comosus (L). Merril) cv. Pérola. Revista Brasileira de Fruticultura, Cruz das Almas, v. 14, n. 2, p. 1-4, 1992.

PRAXEDES, C. S.; SILVA JÚNIOR, A. F. da; FIGUEIREDO, F. L.; FIGUEIREDO, M. de L.; CÂMARA, F. A. A.; OLIVEIRA, O. F. Efeito do ANA e do AIA no estiolamento in vitro do abacaxi cv. Pérola. In: CONGRESSO BRASILEIRO DE FRUTICULTURA, 16., 2000, Fortaleza. Resumos... Fortaleza: Sociedade Brasileira de Fruticultura, 2000. p. 7.

SÁ, M. E. L. de; PEREIRA, F. D.; BRAGA, M. F.; MUSTAFÁ, P. C.; ALVES, A. P. Propagação in vitro de abacaxi (Ananas comosus) por meio de segmentos estiolados. In: CONGRESSO BRASILEIRO DE FRUTICULTURA， 16., 2000, Fortaleza. Resumos... Fortaleza: Sociedade Brasileira de Fruticultura, 2000. p. 21.

SITA, L. G.; SINGH, R.; IYER, C. P. A. Plantlets through shoot-tip culture in pineapple. Current Science, Bombay, v. 43, n. 22, p. 724-725, 1974.

ZEPEDA, C.; SAGAWA, Y. In vitro propagation of pineapple. HortScience, Alexandria, v. 16, n. 4, p. 495, 1981. 